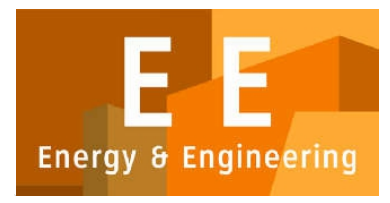

PAPER - OPEN ACCESS

\title{
Penataan Kembali Ruang Terbuka Pada Kawasan Pantai Cermin Sebagai Tujuan Wisata Tepi Air
}

\author{
Author $\quad$ : Rahma Wardani Siregar dan B O Y Marpaung \\ DOI $\quad: 10.32734 /$ ee.v2i1.401 \\ Electronic ISSN $\quad: 2654-704 X$ \\ Print ISSN : :2654-7031
}

Volume 2 Issue 1 - 2019 TALENTA Conference Series: Energy \& Engineering (EE)

This work is licensed under a Creative Commons Attribution-NoDerivatives 4.0 International License.

Published under licence by TALENTA Publisher, Universitas Sumatera Utara 


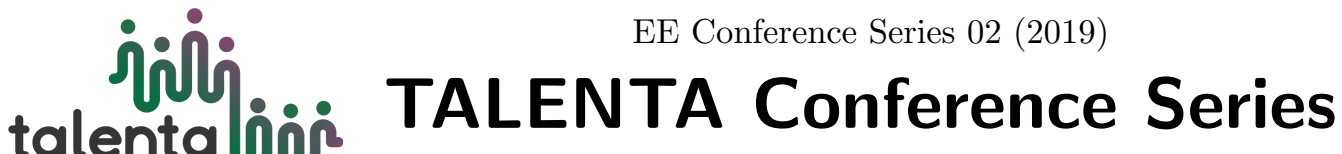

Available online at https://talentaconfseries.usu.ac.id

\section{Penataan Kembali Ruang Terbuka Pada Kawasan Pantai Cermin Sebagai Tujuan Wisata Tepi Air}

\author{
Rahma Wardani Siregar ${ }^{1}$, B O Y Marpaung ${ }^{2}$ \\ ${ }^{1}$ Magister Teknik Arsitektur, Fakultas Teknik, Universitas Sumatera Utara \\ ${ }^{2}$ Departemen Arsitektur, Fakultas Teknik, Universitas Sumatera Utara Jalan Perpustakaan Gedung J, Medan 20155 \\ rahmasiregar29@gmail.com, beny.marpaung@usu.ac.id
}

\begin{abstract}
Abstrak
Kawasan Pantai Cermin merupakan salah satu kawasan tepi pantai yang terletak di Kabupaten Serdang Bedagai, Sumatera Utara. Dalam perkembangnya kawasan ini akan menjadi kawasan wisata tepi air yang ramai di kunjungi masyarakat dari berbagai daerah. Kondisi ruang terbuka yang ada di kawasan ini tidak dimanfaatkan sesuai fungsinya sebagai ruang rekreasi yang bertujuan untuk destinasi wisata tepi air. Sebagai wisata tepi air kawasan Pantai cermin sebaiknya memberikan ruang terbuka yang dapat dinikmati oleh pengunjung dari berbagai aspek. Penelitian ini akan menggunakan metode kualitatif yaitu dengan melakukan observasi langsung pada kawasan Pantai Cermin, lalu mengumpulkan data dan melakukan analisa perencanaan. Hasil dari anlisa akan memberikan solusi dalam penataan kembali ruang terbuka di kawasan Pantai Cermin. Konsep perencanaan tersebut dengan menekankan nilai ruang terbuka yang aman, nyaman dan dapat dinikmati oleh pengunjung wisatawan. Ruang terbuka tersebut juga harus memberikan dampak baik secara visual maupun kebutuhan. Sehingga Kawasan tepi air pantai cermin menetapkan beberapa lokasi untuk ruang terbuka yang dapat dinikmati oleh semua kalangan pengunjung, dengan menata jalur promenade, boardwalk dan jalan setapak yang representatif sehingga meningkatkan kualitas visual pada kawasan, serta menata taman, alun-alun, serta plaza yang lengkap dengan desain lasekap sehingga dapat dinikmati semua kalayangan pengunjung.
\end{abstract}

Kata Kunci : penataan; ruang terbuka; wisata tepi air

\begin{abstract}
The Cermin Beach area is one of the coastal areas located in Serdang Bedagai Regency, North Sumatra. In the development of this area will be a waterfront tourist area that is crowded by people from various regions. The condition of open space in this area is not utilized according to its function as a recreational space which aims for waterfront tourism destinations. As a waterfront tourism mirror area, it should provide open space that can be enjoyed by visitors from various aspects. This study will use qualitative methods, namely by conducting direct observations on the Pantai Cermin area, then collecting data and conducting planning analysis. The results of the analysis will provide a solution in realigning open space in the Cermin Beach area. The planning concept emphasizes the value of open space that is safe, comfortable and can be enjoyed by tourist visitors. The open space must also have an impact both visually and in need. So that the mirror beach waterfront area establishes several locations for open spaces that can be enjoyed by all visitors, by arranging a representative promenade, boardwalk and pathway so as to enhance the visual quality of the area, as well as arranging a complete garden, square and plaza. with a lasekap design so that it can be enjoyed by all visitors.
\end{abstract}

Keywords : arrangement; open spces; waterfront tourism 


\section{Pendahuluan}

Ruang terbuka merupakan ruang yang direncanakan karena kebutuhan akan tempat-tempat pertemuan dan aktivitas bersama di udara terbuka ( [3] Mildawani, 2012). Ditinjau dari bentuk fisiknya ruang terbuka dapat berupa ruang terbuka hijau dan ruang terbuka binaan. Ruang terbuka hijau terdiri dari kawasan yang didominasi oleh tumbuhan yang dibina guna sebagai perlindungan keseimbangan ekosistem, sedangkan ruang terbuka binaan merupakan kawasan yang berupa ruang rekreasi, ruang pedestrian, plaza, dan lain sebagainya.

Kawasan Pantai cermin adalah salah satu objek wisata tepi air yang banyak dikunjungi oleh masyarakat karena merupakan area rekreasi ruang terbuka dan memiliki panorama yang indah. Kondisi eksisting kawasan Pantai cermin memiliki Ruang terbuka yang terdiri dari ruang terbuka hijau dan ruang terbuka biru. Ruang terbuka hijau pada kawasan ini berupa area tepi pantai, sedangkan ruang terbuka biru berupa pantai. Area ruang terbuka di kawasan pantai cermin tidak ditata dan dimanfaatkan semaksimal mungkin sebagai ruang publik yang aman dan nyaman.

Peraturan Presiden No. 51 Tahun 2016 tentang batas sepadan pantai menyatakan bahwa Sempadan Pantai adalah daratan sepanjang pantai yang lebarnya proporsional dengan bentuk dan kondisi fisik pantai, minimal 100 meter dari titik pasang tertinggi ke arah darat. Hal ini guna sebagai akses ruang publik dan perlindungan terhadap ekosistem pesisir pantai dalam mencegah resiko terkena abrasi, banjir, atapun tsunami. Kondisi eksisting ruang terbuka khususnya area tepi pantai merupakan area yang dimanfaatkan sebagai fungsi komersil dengan berdirinya bangunan permanen seperti restauran dan penginapan dengan jarak \pm 5 meter dari bibir pantai. Hal ini mengurangi fungsi dari ruang terbuka untuk menikmati pemandangan secara langsung. Terlebih lagi akses ruang terbuka di sepanjang kawasan Pantai Cermin terbatas untuk dilalui wisatawan karena masing-masing fungsi komersial memiliki privasi sendiri. Dalam perkembanganya ruang terbuka pada kawasan Pantai cermin baik ruang terbuka hijau maupun ruang terbuka non hijau perlu ditata kembali menekankan nilai ruang terbuka yang aman, nyaman dan dapat dinikmati oleh pengunjung wisatawan. Ruang terbuka tersebut juga harus memberikan dampak baik secara visual maupun kebutuhan. Sehingga Kawasan Pantai Cermin merupakan kawasan wisata tepi air yang dapat semua kalayangan pengunjung baik dari segi lansekap, visual, dan promenade.

\section{Studi Banding}

Peneliti melakukan studi kasus sejenis pada Kawasan Alexandria merupakan kawasan wisata waterfront yang terletak di Virginia, United States (Gambar 1). Kawasan Alexandria Waterfront merupakan kawasan bersejarah kota tua yang memilki daya tarik pengunjung yang tinggi. Ruang terbuka sangat memberikan dampak baik secara visual maupun kebutuhan, Sehingga Alexandria Waterfront menetapkan beberapa lokasi untuk ruang terbuka yang dapat dinikmati oleh semua kalangan pengunjung.

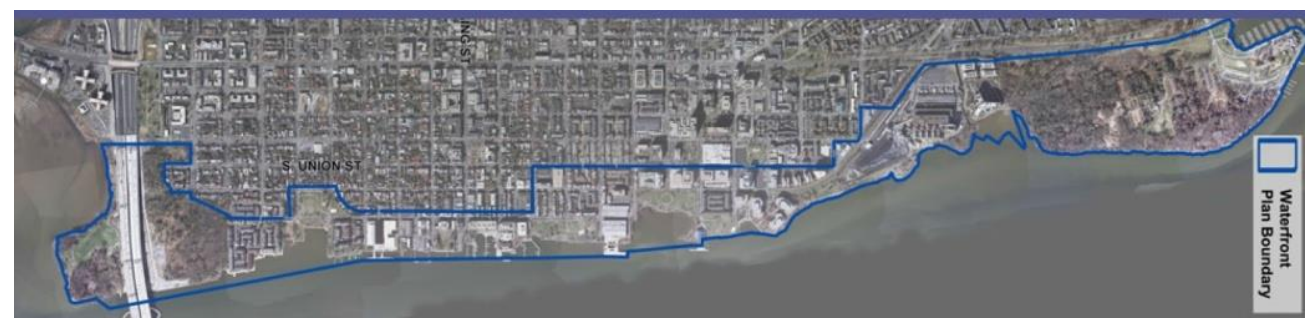

Gambar 1. Eksisting Kawasan Alexandria Waterfront

Sumber :[1] City of Alexandria Department of Planning and Zoning, 2011

Dalam perencanaan ruang terbuka Alexandria Waterfront merencanakan untuk menciptakan kawasan ruang terbuka yang ditata kembali dengan memadukan nilai sejarah. Ruang terbuka tersebut harus dapat dinikmati oleh semua pengunjung dari berbagai aspek. Rencana ini dengan menata kembali jalur promenade, boardwalk dan jalan setapak yang representatif sehingga meningkatkan kualitas visual pada kawasan, dan menata taman, alun-alun, serta plaza yang lengkap dengan desain lasekap sehingga dapat dinikmati semua kalayangan pengunjung.

Berdasarkan site plan (Gambar 2), kawasan Alexandira Waterfront di bagi menjadi 5 kawasan ruang terbuka yang didesain berdasarkan masing-masing sejarah kawasan yaitu, Rivergate City Park (1), Oronoco Bay Park (2), Founders Park (3), Fitzgerald Square (4), Point Lumley Park (5). 


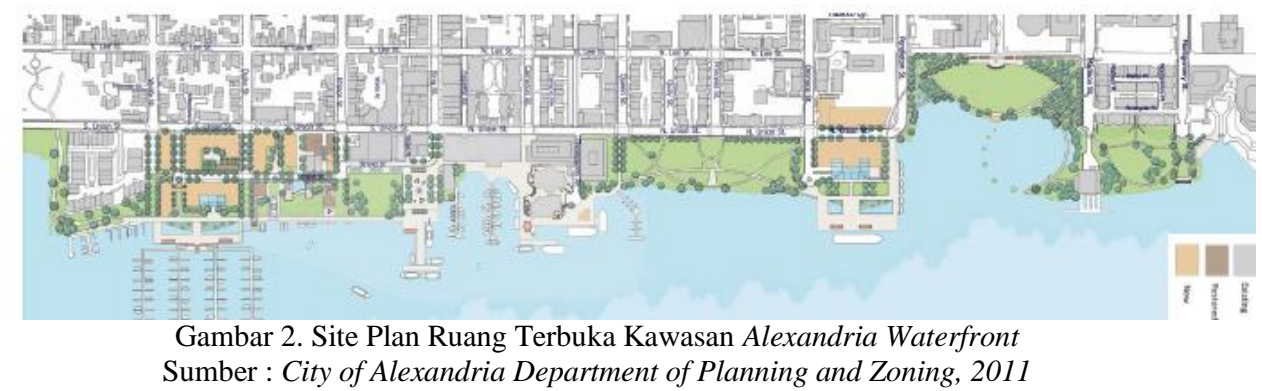

Pedoman ruang terbuka pada kawasan Alexandria mempunyai konsep perancangan dengan merencanakan dan merancang ruang publik yang alami seperti meningkatkan kualitas dan memelihara akses dan ruang publik. Beberapa konsep yang direncankan dan diterapkan oleh perencana Alexandira Waterfrot untuk merancang ruang terbuka tertera sebagai berikut :

- $\quad$ Ruang terbuka di rancang dengan dengan meningkatkan lansekap seperti memperkuat kualitas jalur berjalan yang di teduhi pepohonan serta menganti riprap sesuai garis pantai alami. Penambahan bangku taman dan penerangan pada area taman tersebut. Hal ini di implemetasikan pada Founders Park, Orino Park, Point Lumley Park, dan Rivergate city Park.

- Menyediakan cafe outdoor dan retail- retail souvenir pada taman Fitzgerald Square yang bersih, nyaman, aman, serta dapat menikmati panorama pantai.

- $\quad$ Pada eksisting Prince Street End jalur promenade dan boardwalk tidak terhubung dan kondisi riprap yang masih belum tertata. Perencanaan pada kawasan ini melakukan sistem yang terhubung seperti boardwalk dan promanade pada seluruh area ruang terbuka sehingga publik dapat menikmati pemandangan panorama sepanjang pantai Alexandria (Gambar 3).
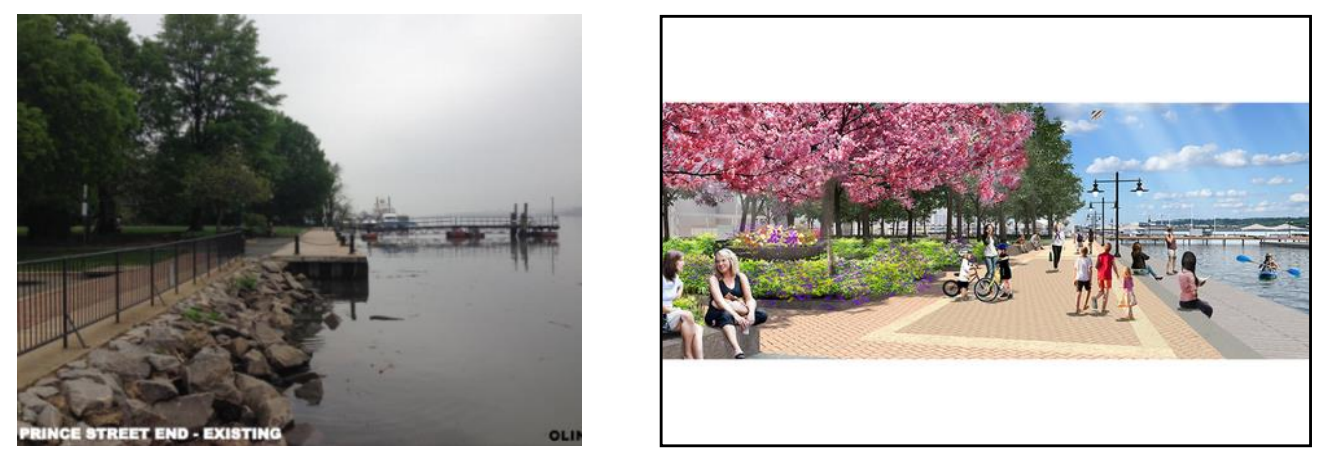

Gambar 3. Eksisting (kiri) dan Ilustrasi (kanan) Prince Street End Kawasan Alexandria Waterfront Sumber : [1] City of Alexandria Department of Planning and Zoning, 2011

- $\quad$ Pada eksisting area Rivergate park minimnya area teduh karena pepohonan yang mulai usang, minimnya tumbuh-tumbuhan seperti rumput, riprap yang belum tertata, dan minimnya area duduk atau bangku taman untuk menimati panorama pantai. Perencanaan pada kawasan ini dengan ditanami rumput yang dihiasi dengan pohon yang cocok untuk kenikmatan pasif pada area pinggir pantai dan ruang terbuka, membuat bangku taman untuk meningkatkan kenikmatan taman dari batu alam dan riprap untuk menikmati acara komunitas yaitu mendayung perahu. Selain itu menjaga koneksi yang kuat untuk jalurnya pejalan kaki dan pelari di sepanjang tepi pantai (Gambar 4). 

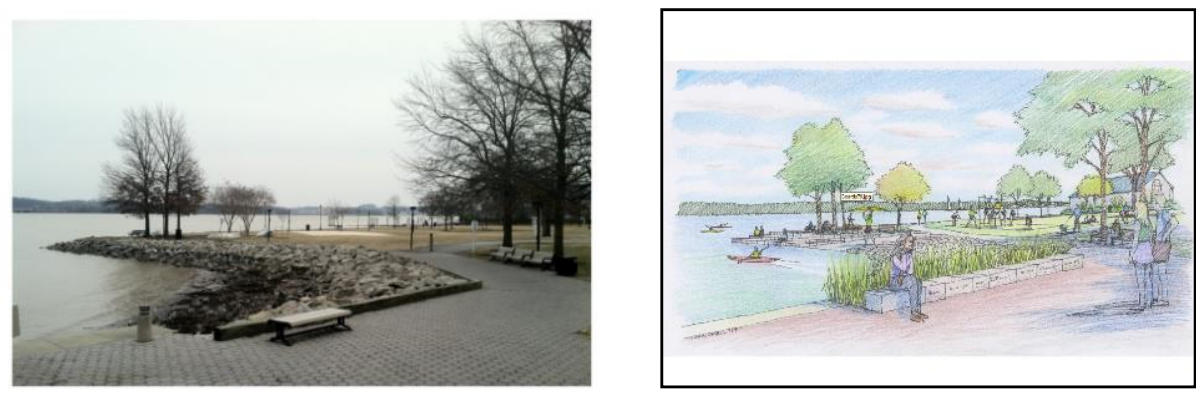

Gambar 4. Eksisting (kiri) dan Ilustrasi (kanan) Rivergate park Kawasan Alexandria Waterfront Sumber : [4] Implementation of the waterfront Alexandria Plan, 2014

\section{Metodologi Penelitian}

Metode penelitian yang digunakan pada penelitian ini adalah kualitatif yaitu dengan melakukan observasi langsung pada kawasan penelitian. Data yang dikumpulkan berupa data primer dan data sekunder. Pengumpulan data primer berupa wawancara langsung pada wisatawan dan tokoh masyarakat, dokumentasi, serta menggambar ulang peta kawasan perencanaan. Sedangkan data sekunder diperoleh dari kajian teori, studi banding sejenis, dan kebijakankebijakan.

\section{Kajian Perencanaan dan Perancangan}

Lokasi perencanaan terletak di desa Pantai Cermin Kanan Kecamatan Pantai Cermin, Kabupaten Serdang Bedagai (Gambar 5). Menurut Rencana Tata Ruang Wilayah (RTRW) Kabupaten Serdang Bedagai Tahun 2013-2033, pariwisata di Kabupaten Serdang Bedagai umumnya yang paling banyak diminati adalah mengunjungi pantai, salah satunya adalah kawasan Pantai Cermin yang terdapat di desa Pantai Cermin Kanan Kecamatan Pantai Cermin khususnya kwasan tepi air. Kawasan perencanaan memiliki luas \pm 650 ha.
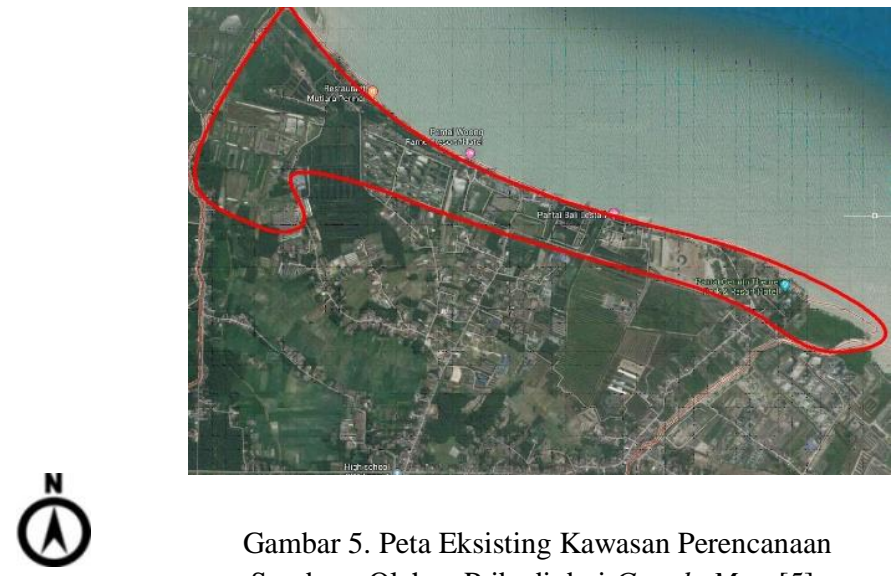

Gambar 5. Peta Eksisting Kawasan Perencanaan Sumber : Olahan Pribadi dari Google Maps[5]

Berdasarkan kondisi eksisting Ruang terbuka pada kawasan Pantai Cermin belum di tata dan direncanakan sesuai perencanaan yang baik khususnya pada kawasan tepi pantai. Pada kawasan sepanjang tepi pantai cermin terdapat beberapa ruang terbuka yang lansekapnya tidak di tata dengan sesuai fungsinya, bahkan eksisting ruang terbuka pada kawasan tepi pantai didominasi fungsi komersial. Fungsi komersial tersebut berupa bangunan restauran yang hanya dapat dinikmati oleh pengunjung yang memasan makanan di restaurant tersebut dan penginapan (Gambar 5). Dengan didominasi fungsi komersial nilai ruang terbuka pada area tepi pantai menjadi berkurang dari berbagai aspek. Aspek tersebut seperti, visual promenade, dan ruang publik yang dapat dinikmati oleh pengunjung. hanya dapat dinikmati oleh pengunjung yang memasan makanan di restaurant tersebut

Kawasan tepi Pantai Cermin belum menciptakan ruang terbuka publik yang dapat dinikmati oleh semua pengunjung. Pada kawasan Pantai cermin belum dijumpai taman yang dilengkapai dengan lansekap yang memadai serta beberapa 
fasilitas ruang terbuka seperti, bangku taman, penerangan taman, dan peneduh. Pengunjung juga tidak bisa menikmati sepanjang kawasan tepi air karena konektivitas pada kawasan waterfront pantai cermin masih per blok-blok. Hal ini menyebakan perlunya penataan kembali ruang terbuka hijau pada kawasan Pantai cermin agar menjadi ruang publik yang baik.

Perencanaan ruang terbuka diciptakan sebagai ruang publik yang harus dapat dinikmati oleh semua pengunjung dari berbagai aspek. Penataan kembali ruang terbuka pada kawasan tepi Pantai Cermin dengan merencanakan ruang publik berupa area piknik seperti, plaza, family park, teen park, amphytheater, taman bermain anak, area flying fish and banana boat. Serta promenade yang dapat terkoneksi sepanjang tepi pantai. Selain itu pada kawasan Pantai Cermin juga ruang terbuka yang berupa objek wisata yaitu amusement park dan wisata mangrove (Gambar 6)

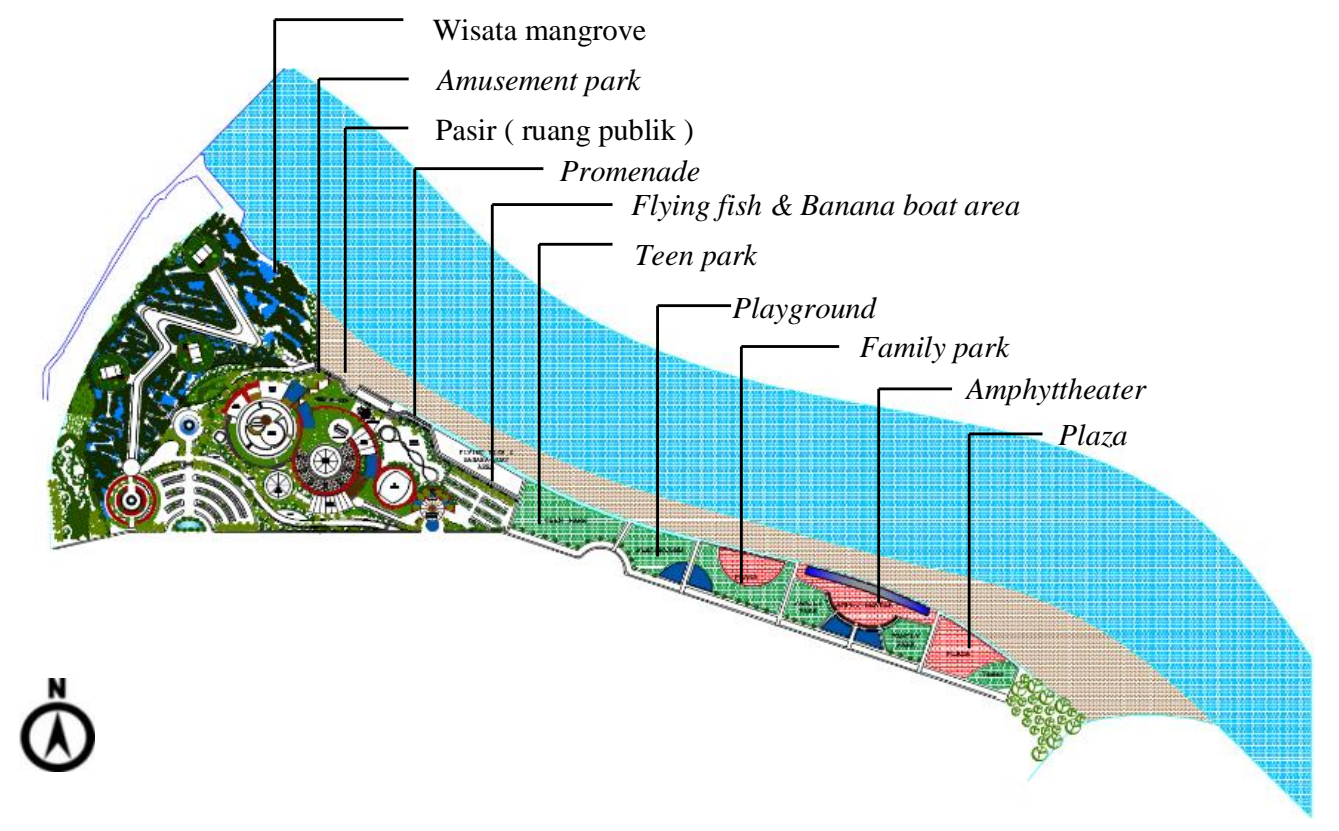

Gambar 6. Peta Perencanaan Ruang Terbuka Kawasan Pantai Cermin Sumber : Olahan pribadi

Konsep perencanaan ruang terbuka di rencanakan dengan meningkatkan lansekap seperti memperkuat kualitas jalur berjalan yang di teduhi pepohonan serta menganti riprap sesuai garis pantai alami. Penambahan bangku taman dan penerangan pada area taman dapat meningkatkan kenyamanan pengunjung. Penggunanaan material juga diperhitungkan dalam merencanakan ruang terbuka, seperti menggunakan paving block dan gras block yang dapat menyerap air serta mengurangi emisi karbon. Pemilihan pohon yang berfungsi sebagai peneduh dan menciptakan kadar oksigen yang tinggi. Perencanaan dan perancangan ini akan menjadi konsep dalam menata kembali ruang terbuka di kawasan Pantai cermin yang dapat meningkatkan kualitas wisata tepi air.

\section{Kesimpulan}

Penataan kembali ruang terbuka pada kawasan Pantai Cermin sebagai tujuan wisata tepi air diwujudkan dengan menciptakan ruang terbuka publik yang dapat dinikmati oleh semua pengunjung. Dengan merencanakan ruang publik berupa area piknik dan objek wisata. Selain itu meningkatkan lansekap seperti memperkuat kualitas jalur berjalan yang di teduhi pepohonan, penambahan fasilitas taman dan penggunanaan material yang ramah lingkungan akan meningkatkan kualitas wisata tepi air dari berbagai aspek. 


\section{Referensi}

[1] City of Alexandria Department of Planning and Zoning, (2011). Alexandria's Waterfront Plan "A Summary".

[2] City Council Hearing, (2014). Implementation of Waterfront Small Area Plan

[3] Mildawani, I., Susilowati, D., \& Schiffer, L. R. (2012). Aplikasi Sistem Informasi Geografis (SIG) dalam Analisis Pemanfaatan dan Pengelolaan Ruang Terbuka Hijau Kota (RTHK) Studi Kasus Kota Depok.

[4] Implementation of the waterfront Alexandria Plan, (2014). Alexandria's Waterfront Plan "A Summary".

[5] Google Maps, (2018). Peta Eksisting Kawasan Perencanaan. 